\title{
Cockatoo Island: pit dewatering and wall depressurisation behind critical seawall infrastructure
}

\author{
CL Powell Newmont Australia, Australia
}

J Hall AQ2 Pty Ltd, Australia

\begin{abstract}
The Cockatoo Island iron ore mine located in the Kimberley of Western Australia has had a history of instability related to critical seawall infrastructure over the last 15 years. This is in part due to the challenging setting of excavating an open pit directly adjacent to the sea. Seawall infrastructure has been constructed over thick very soft marine sediments to enable mining to progress below sea level over the years. Following suspension of mining in 2016 the dewatering pumps were decommissioned and the pit was allowed to flood. Planned resumption of mining in 2017 required that the pit be dewatered and then cutback and deepened.

A critical factor in the planned resumption of mining was the impact of water and pore pressure on the stability of the pit slope during initial pit lake dewatering and then subsequent mine development. The earthen seawall structure is founded on $20 \mathrm{~m}$ of very soft coralline sediments and forms the crest of the hanging wall of the pit. The pit slope is formed in these sediments and underlying extremely weak saprolite. The pit lake had essentially recovered to sea level and the pit wall sediments were fully saturated. A carefully reasoned approach was required to dewater the pit (and depressurise the pit walls) to prevent failure of the slope and destabilisation of the seawall.

An engineered approach was developed by the mining company's geotechnical engineer in conjunction with a hydrogeological consultant to develop a practical hydro-geotechnical solution and implement a successful pit wall depressurisation scheme. This involved iterative numerical geotechnical slope stability modelling and groundwater modelling using data from several vertically stacked vibrating wire piezometers (VWP) to calibrate the models. Initial calibration was against longer-term (pseudo-steady state) data from the period of pit flooding and then against transient pore pressure responses as dewatering of the pit lake commenced. Calibrated models were then used to predict pore pressures and slope stability for various pit development scenarios assuming both natural pit wall drainage (seepage flow to pit faces) and enhanced drainage using sand drains.

A life-of-mine pit development and pit wall depressurisation plan was developed that included pit lake dewatering and detailed monitoring of piezometers and slope performance (automated prism monitoring and slope radar surveillance) to provide ongoing validation and calibration of the pore pressure and slope stability models and to ensure that these remained within acceptable limits.
\end{abstract}

The adopted approach resulted in successful controlled depressurisation and stable pit slopes. Unfortunately, despite the dewatering scheme being implemented successfully, other factors resulted in the project remaining in care and maintenance. The pit has since been allowed to flood.

Keywords: open pit, slope stability, dewatering, depressurisation, seawall

\section{Introduction}

The Cockatoo Island iron ore mine, located in the Kimberley region of Western Australia (WA), has one of highest grade hematite deposits in the world. It is also one of the oldest iron ore mines in Australia with development beginning in the 1930s (Smith 1979). Initial mining of the ore adjacent to the sea was progressed by BHP to sea level before closure of the mine in 1986. Construction of seawall infrastructure 
shown in Figure 1 allowed mining to recommence and progress below sea level in the early 2000s, however, in 2016 mining was again suspended. Although dewatering activities continued during care and maintenance, these were interrupted at various times eventually causing flooding of the pit to near sea level. New interest in the mine in 2017 led to initiatives to recommence operations including dewatering of the pit and a major a pit cut-back.

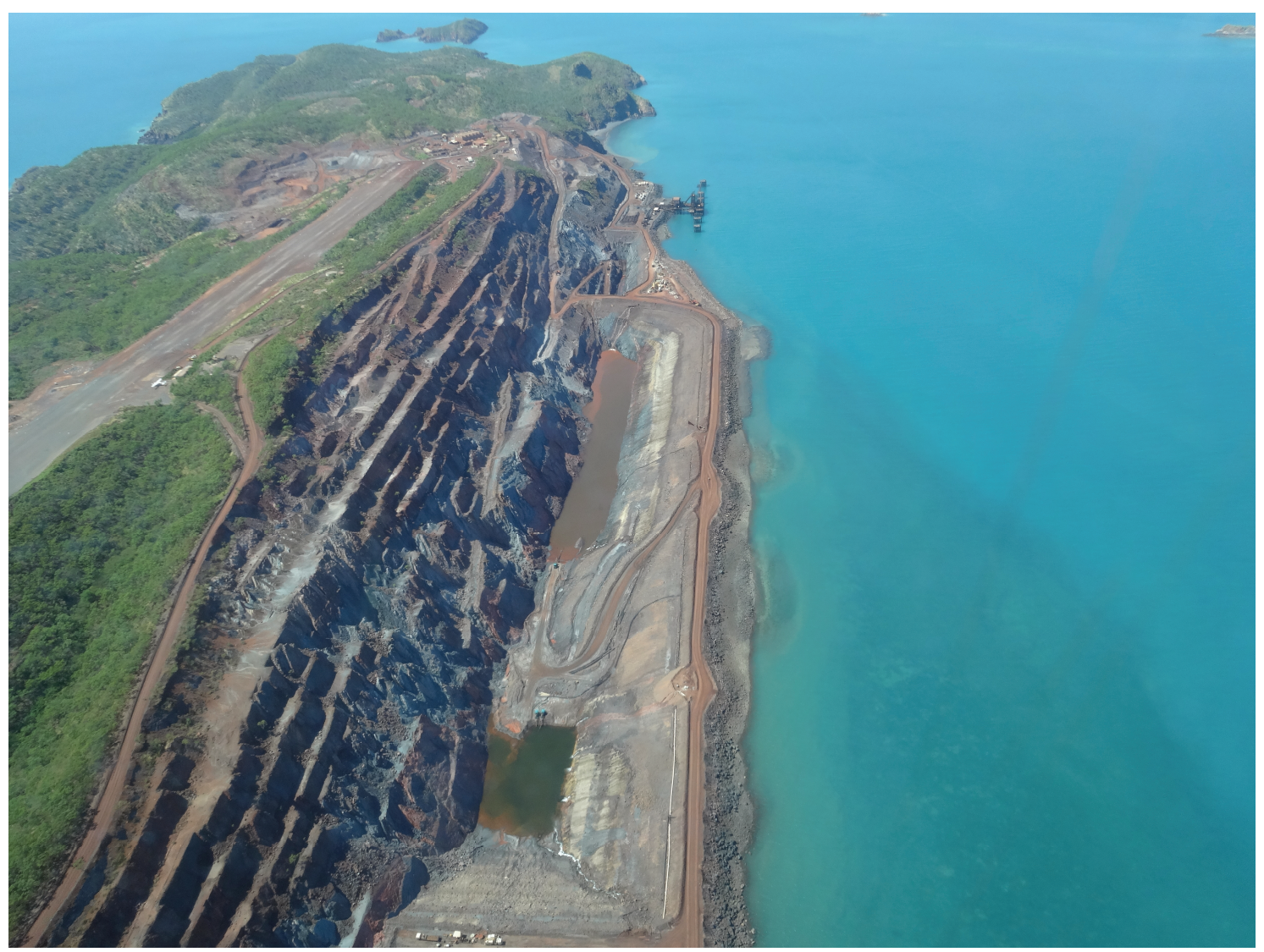

Figure 1 Cockatoo Island open pit during mining of Stage 4

During previous mining behind the seawall (2000-2016) the operation developed a history of hanging wall instability related to critical seawall infrastructure that was constructed over a thick layer of very soft coralline sediments. A key success factor in resuming operations involved ensuring integrity of the seawall during dewatering and subsequent mining of the pit. Any failure of the seawall would have resulted in the preclusion of mining similar to the situation that occurred on neighbouring Koolan Island in 2014. Maintaining integrity of the seawall was also subject to much scrutiny and concern including from the WA government Department of Mines, Industry Regulation and Safety (DMIRS) who were provided with regular updates during dewatering and local traditional owners.

A carefully managed and sequenced engineered approach was developed to control slope stability, which was observed to be intrinsically linked to pore pressure within the sediments that form the hanging wall pit slope. The negative effect increased pore pressure can have on slope stability is well documented, including by Sullivan (2007). Adding to this challenge was the proximity of the pit wall to the sea and the consequent variable recharge impact of local tidal fluctuations (reaching up to $10 \mathrm{~m}$ ) which produced cyclical pore pressure responses within seawall foundations and pit walls. Pore pressure distributions and fluctuations were critical factors in the stability analysis of the seawall and hanging wall.

Pore pressure modelling was undertaken to gain a better understanding of the groundwater changes and to predict porewater responses during dewatering. Model predictions were used to help predict slope stability and help create a dewatering schedule. Monitoring data including from vibrating wire piezometers (VWPs), prisms and slope stability radar were used to track pore pressure and ground deformation. 
An allowance within the dewatering schedule was provided in case additional time was required for depressurisation.

Learnings from the initial pit dewatering helped in the refinement of pit wall cut-back design, which subsequently enabled access to additional ore at the toe of hanging wall slope. A key depressurisation design feature refined during the modelling process was a passive vertical sand drain solution used to lower pore pressure in the coralline sediments over the life-of-mine (LOM) by opening a drainage pathway to an underlying free-draining material layer.

Figure 2 shows a plan view of the Cockatoo Island open pit operation identifying various stages of seawall construction separating the sea and the pit excavation.

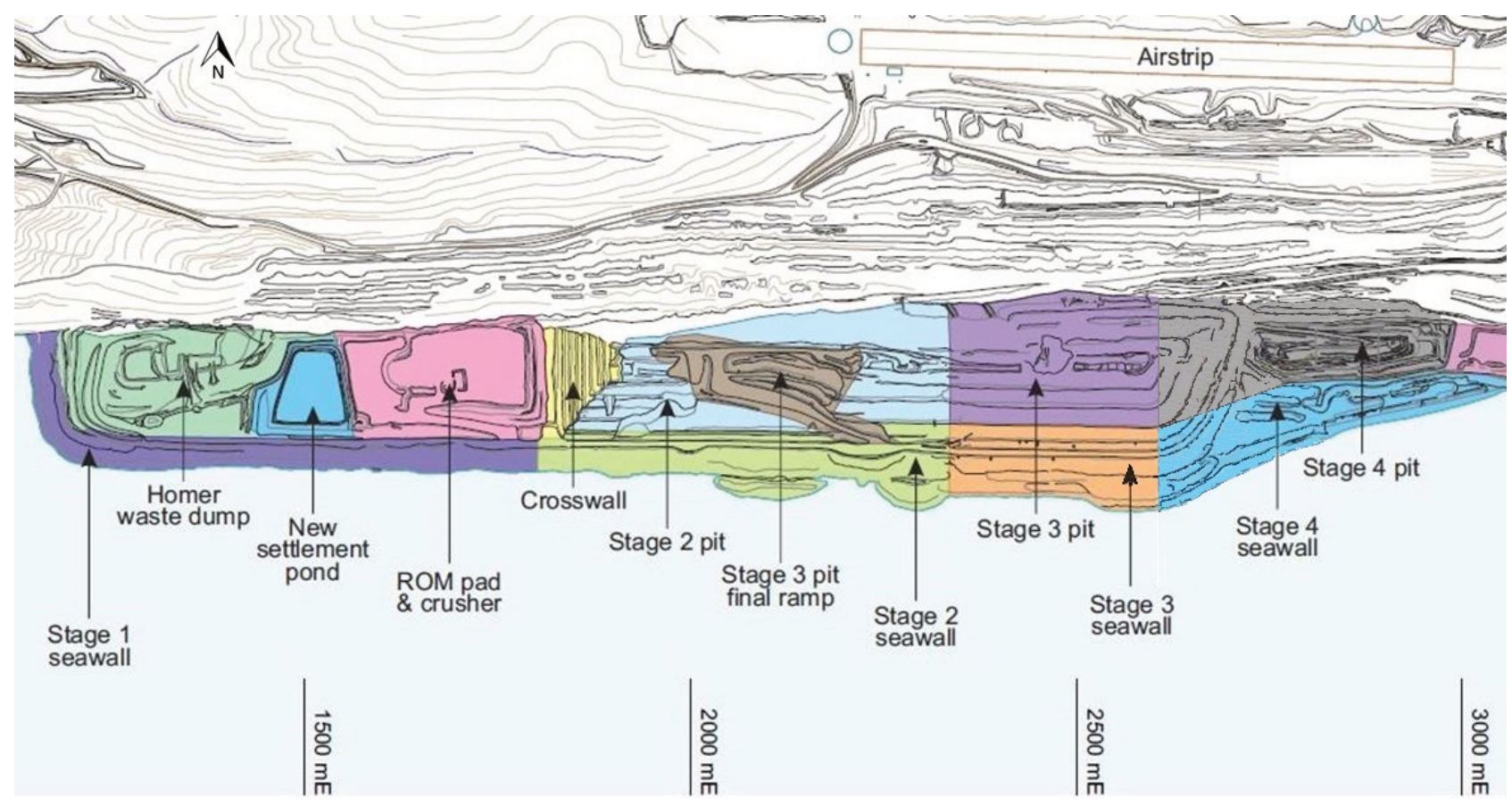

Figure 2 Plan view of open pit operations showing site layout including various stages of pit/seawall

\section{Seawall infrastructure and pit description}

Seawall infrastructure to enable mining below sea level was constructed in four stages starting in 2002. Sequential construction of adjoining sections enabled continuous mining behind the seawall until suspension of mining operations in 2016. Construction of the seawall embankment was performed using a staged loading approach, where timing of the placement of fill layers was controlled to allow strength gain within underlying foundation sediments to occur. Different solutions where used in various stages of construction to provide barriers against water ingress. Low permeability barrier solutions include compacted clay core material, sheet piles and grout injection or a combination of these. All four contiguous sections of seawall extend over $2 \mathrm{kms}$ along the strike of the orebody. As mining progressed, initial stages of the open pit were used as in-pit waste dumps that currently extend over one third of the length of the pit.

Table 1 lists the different stages of seawall construction and the low permeability barrier solution used in each case.

The seawall is located on the hanging wall side of the open pit and is founded on in situ compressible sediments. Low permeability barrier solutions are either keyed into or extended through the top of the compressible sediments.

Construction of the seawall enabled mining of the orebody to $-50 \mathrm{mRL}$, equivalent to $50 \mathrm{~m}$ below the elevation of the lowest tide $(0 \mathrm{mRL})$. The footwall of the pit to the north is approximately $170 \mathrm{~m}$ high while the hanging wall supporting the seawall is $63 \mathrm{~m}$ high. Slope angles within hanging wall geological units 
above competent rock are presented within Table 2 . The design batter/berm configuration within these units comprises $5 \mathrm{~m}$ wide berms every 10 vertical metres (following batter angles in Table 2).

Table 1 Low permeability barriers used in different stages of seawall construction

\begin{tabular}{ll}
\hline Seawall construction stage & Type of low permeability barrier \\
\hline Stage 1 & Clay core \\
Stage 2 & Clay core \\
Stage 3 & Clay core and sheet piles \\
Stage 4 & Bentonite grout injection \\
\hline
\end{tabular}

Table 2 Hanging wall slope design angles

\begin{tabular}{ll}
\hline Geological unit & Pit slope batter angle $\left(^{\circ}\right)$ \\
\hline Rockfill & 26.5 \\
Beach sands, coralline sediments & 25 \\
$\begin{array}{l}\text { Marine sediments, marine clay, } \\
\text { hematite scree, elgee siltstone }\end{array}$ & 35 \\
\hline
\end{tabular}

\section{Geology}

Local geology is characterised by an inverted sedimentary rock sequence and various marine sediments formed in coastal waters. The sedimentary rock sequence strikes east-west and contains the $30 \mathrm{~m}$ thick hematite orebody. The orebody dips roughly 55 degrees towards the south and continues at depth beneath the sea. The hanging wall side of the pit borders the sea and comprises thin granular and thick cohesive sediment layers above a layer of hematite scree. This is underlain by extremely weak saprolite followed by strong/competent hematite rock. The cross-section at $2550 \mathrm{mE}$ presented in Figure 3 shows typical geology.

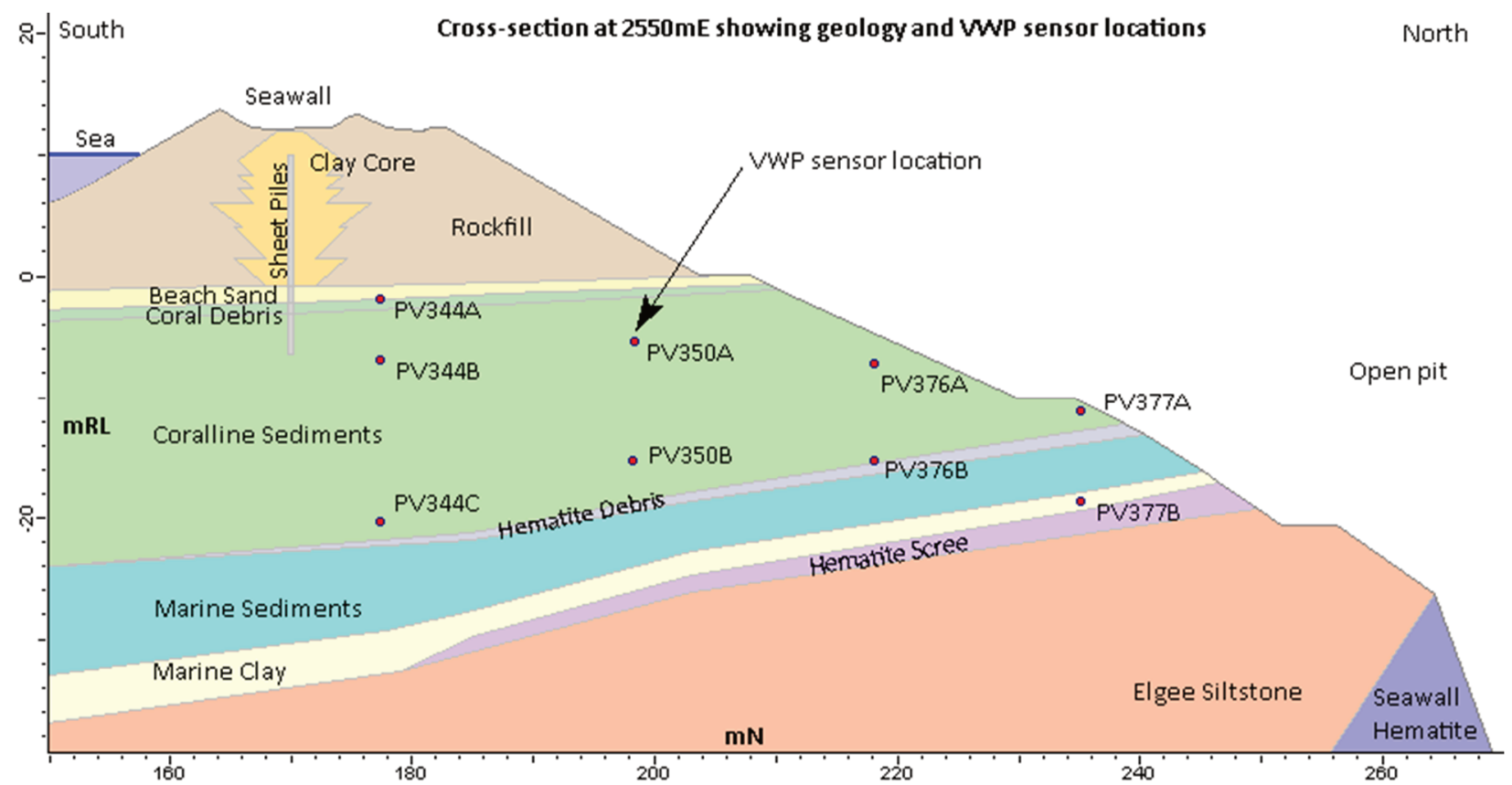

Figure 3 Cross-section at $2550 \mathrm{mE}$ showing typical geology and example of vibrating wire piezometers (VWP) sensor layout 
Table 3 shows the stratigraphic sequence and typical thicknesses of sediments forming the foundation material of the seawall, from highest to lowest in elevation.

Table 3 Seawall foundation sediment units, typical thicknesses and cohesive characteristics

\begin{tabular}{lll}
\hline Seawall foundation sediment units & Typical thickness & Character \\
\hline Coral debris/beach sand & $0.5-2 \mathrm{~m}$ & Non-cohesive \\
Coralline sediments & $20 \mathrm{~m}$ & Cohesive \\
Marine sediments & $4 \mathrm{~m}$ & Cohesive \\
Marine clay & $1 \mathrm{~m}$ & Cohesive \\
Hematite scree & $1-3 \mathrm{~m}$ & Non-cohesive \\
\hline
\end{tabular}

The coralline sediments are the most significant material affecting slope stability as they are the weakest and thickest material supporting the seawall embankment. These are characterised as a sandy gravelly silty clay of low to very high plasticity. The fines content of the coralline sediments averages approximately $50 \%$ with the remaining portion consisting of sand and coral fragments. Due to the nature of deposition, significant local variations in particle size distribution (PSD) exist locally throughout the material. Table 4 presents PSD and Atterberg limit laboratory test results for coralline sediments material.

During initial excavation of the pit to form the hanging wall, slope stability was assessed using effective stress analysis (ESA). Interpreted effective strength of the coralline sediments was initially assessed by consultants to include cohesion element, $c^{\prime}$. However, after significant historic slope instability this was revised to zero coupled with an angle of friction (phi') of $29^{\circ}$. Material strength properties were determined through triaxial tests. Local variability in material strength was highlighted as one element contributing to historic slope failures.

Consolidation within the coralline sediments, as a result of construction, caused a relative gain in undrained strength $\left(c_{u}\right)$ proportional to loading history. Although revised $c_{u}$ values could be calculated, they were not verified in the field. Undrained strength was not used in final dewatering or cut-back assessments.

Table 4 Laboratory particle size distribution and Atterberg limit test results for coralline sediments

\begin{tabular}{llllllll}
\hline & Gravel (\%) & Sand (\%) & Silt (\%) & Clay (\%) & LL (\%) & PL (\%) & PI (\%) \\
\hline No. tests & 54 & 54 & 36 & 36 & 57 & 57 & 57 \\
Max & 72 & 59 & 51 & 37 & 91 & 50 & 70 \\
Min & 1 & 2 & 8 & 2 & 22 & 9 & 9 \\
Ave & 25.1 & 26.2 & 28.3 & 20.0 & 53.2 & 20.7 & 32.2 \\
St. dev. & 16.0 & 15.4 & 9.3 & 7.0 & 18.3 & 6.0 & 16.6 \\
\hline
\end{tabular}

*Atterberg results plot above the A-Line on a plasticity chart $90 \%$ of the time considering available data.

Seawall foundation sediment units other than the coralline sediments played important, but relatively less crucial, roles in the strength offered by material properties. This is also true for materials comprising the seawall embankment itself. Aside from material strength, hydrogeological material properties played an equally important role; either hindering or accelerating drainage pathways through given materials.

\section{$4 \quad$ Hydrogeological setting}

The hydrogeological dynamics within the hanging wall sequence are controlled by two competing features: low permeability (poorly drained) cohesive materials and interspersed high permeability, well-drained horizons. Pit lake flooding resulted from inflow of sea water mostly through the higher permeability 
materials. Pit inflow rates were tide-dependant; up to $300 \mathrm{~L} / \mathrm{s}(\sim 26 \mathrm{ML} / \mathrm{d})$ or more during peak tides. Groundwater flows much more slowly through the cohesive materials underlying the seawall embankment.

VWP data from sensors located in both the cohesive and non-cohesive materials indicate clear fluctuating responses to tidal events, superimposed over a hydraulic gradient from the sea towards the pit.

It is noted that over 50 VWP sensors are installed within the hanging wall slope, generally located along north-south transects across the seawall alignment at approximately $50 \mathrm{~m}$ intervals between each transect. Most sensor installations consist of vertical arrays of either two or three sensors at various depths in fully grouted boreholes. Dataloggers were set to record readings at intervals of one hour or less. The geological cross-section in Figure 3 provides an example of VWP sensor vertical arrays and layout.

Prior to the cessation of previous mining, dewatering and development of the pit lake, the pit had remained dry through many years of operations and pore pressures within the hanging wall sequence were considered to have reached a steady state. This interpretation is supported by measured pore pressure data collected from the extensive array of VWPs. Pore pressures measured in the hanging wall slope profile show clear decreasing trends during and after excavation of the pit on the landward side followed by a generally steady state period within the range of tidally influenced variations.

Previous minor pit inundations had occurred due to cessation in pumping before the major inundation in early 2017. Controlled restart of pumping successfully managed to reduce water levels and enabled pore pressure data collection and monitoring at different VWP locations as the level of the pit lake reduced.

\section{$5 \quad$ Engineered approach to dewatering}

Initial stability assessments predicted that pit stability would largely be governed by the rate of pit lake dewatering and consequent rate and distribution of pore pressure dissipation within the coralline sediments. Due to the cost implications of extended dewatering operations it was necessary to determine an appropriate rate of dewatering that would allow time for adequate pore pressure reduction to mitigate the risk of potential pit slope and seawall failure. This was achieved using an iterative process of predicting the effects of various dewatering rates on pore pressure distribution and then subsequently on slope stability. During dewatering, previously modelled pore pressure predictions were compared with measured VWP data to assess progress. The process essentially involved multiple short-term pore pressure model prediction/validation. Using this approach, it was therefore possible to predict the behaviour of the slope and also provide an opportunity to fine-tune the approach in accordance with increasing confidence based on observations in the field. The methodology was made possible due to the monitoring equipment available onsite in conjunction with modelling software.

\subsection{Initial stability assessments}

Initial assessments to predict slope performance during dewatering made use of available material properties and hydrogeological parameters. Two critical slope sections were selected and used for stability analysis; sections $2550 \mathrm{mE}$ and $2450 \mathrm{mE}$. Construction of slope stability models in Rocscience Slide ${ }^{\mathrm{TM}}$ software was done by importing geometries from 2D slices through a geo-referenced 3D Surpac ${ }^{\mathrm{TM}}$ model in which all relevant boundaries and geological surfaces were displayed. The complex nature of pore pressure distribution within the slope did not justify for a single groundwater surface to be interpreted. Several piezometric surfaces were subsequently interpreted from available VWP data and assigned to designated material layers within the stability model. Due to low assessed factors of safety (FoS) using this method and the difficulty of predicting groundwater changes using geotechnical models alone, it was decided to use a groundwater modelling approach to provide the required degree of confidence and functionality.

\subsection{Hydrogeological model}

The groundwater model was developed based on the available geological model, using the software package Modflow Surfact ${ }^{\mathrm{TM}}$ to undertake 2D vertical slice modelling. Initial hydrogeological parameters 
were assigned to materials according to field and laboratory test results reported in prior studies. When comparing model results to field data collected, it was apparent that further work was required to better understand material properties. Previous flooding events meant that associated changes in pore pressure readings at VWP sensor locations could be used to calibrate the groundwater model. This proved to be a valuable tool to interpret and assign revised material parameters. The calibrated groundwater model enabled predictions of pore pressure distributions to be modelled along the two critical sections at $2550 \mathrm{mE}$ and $2450 \mathrm{mE}$. The grid size of the developed Modflow model was $1 \mathrm{~m} \times 1 \mathrm{~m}$ and pore pressure values could be exported in tabular format and directly imported into the Slide ${ }^{\mathrm{TM}}$ software used for slope stability analysis. To facilitate import and export of pore pressure grid values, geology and material boundaries within the groundwater model were created as geo-referenced replicas of the selected critical sections developed in the geotechnical model. This was facilitated using the DXF export function within Slide ${ }^{\mathrm{TM}}$.

\subsubsection{Model calibration}

Calibration of the groundwater model used pore pressure datasets collected from VWP sensors installed along two cross-sections at $2550 \mathrm{mE}$ and $2450 \mathrm{mE}$. A total of four vertical VWP sensor arrays are located along each of these sections. Geo-referenced sensors are located in upper, mid and lower areas within the coralline sediments providing good spatial coverage. Working with initially derived hydraulic parameters, the model was run to simulate how actual measured timestamped rises and falls in the level of the pit lake affected pore pressure distribution within the model. Hydrographs were then produced at the geo-locations within the model representing VWP sensor locations. Changes to material characteristics produced different shaped hydrographs and results were then compared to actual measured pore pressure reactions to the same fluctuations in the pit lake. A close fit in modelled and actual hydrographs for any particular VWP sensor location indicates an increased likelihood that the model can predict accurate pore pressure variations due to changing conditions.

The calibration process followed an iterative approach to establish a best match between modelled pore pressure distributions and measured pore pressure distributions at discrete VWP locations within each $2 \mathrm{D}$ cross-section. Modifications during calibration included changes to hydraulic conductivity, anisotropy (i.e. the ratio of horizontal to vertical hydraulic conductivity) and storativity. Overall, the calibrated model well replicated the measured data, although there were several VWP sensor locations where the calibration match was not so good. These tended to be locations very close to the pit face (within several metres). Reasons for observed variations are considered to include naturally occurring variations in material properties and proximity to the pit face.

Figure 4 shows an example of early calibration run output (Run 27, UC1 and UC2) compared to actual measured pore pressure at VWP sensor location PV350B. The results for Run 27 provide a good match compared to measured pore pressure during pit inundation and subsequent partial dewatering.

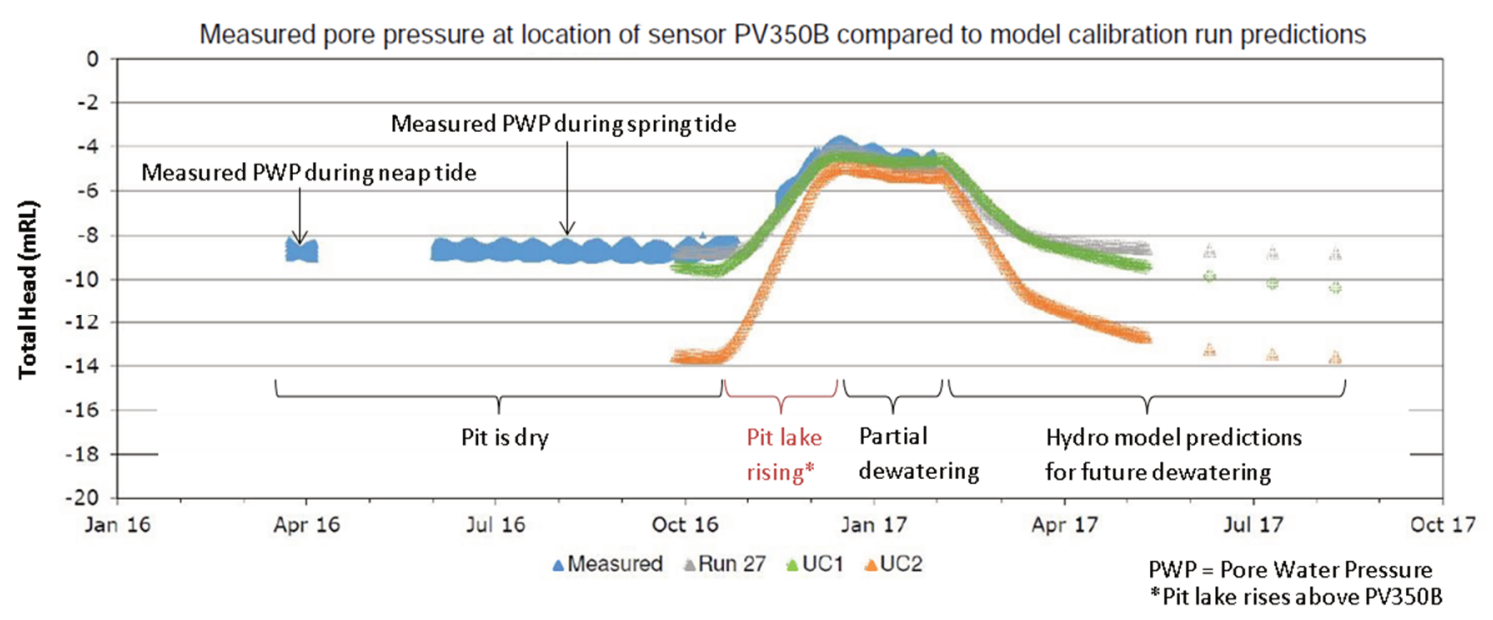

Figure 4 Example of early calibration run output compared to measured pore pressure at sensor PV350B 


\subsection{Predictive slope stability assessments}

Slope stability models were constructed and run to simulate the impacts on stability of various dewatering scenarios considered (see pit lake drawdown rates in Section 5.3.1). This process was used to select suitable dewatering rates according to an acceptable risk profile agreed by project stakeholders.

Evaluation of potential future scenarios focused on several aspects while attempting to provide greatest benefit to realise increased dewatering rates. Focus was provided according to the following strategies:

- Evaluation of high rate dewatering as a priority.

- Evaluation of slope geometry to determine potential dewatering opportunities.

- Evaluation of opportunities to speed up dewatering through different material types.

The modelling process highlighted the potential for very low calculated FoS and the need for careful monitoring to evaluate performance of the slope during the dewatering stage, especially when dewatering through the coralline sediments profile.

\subsubsection{Rate of dewatering}

Stability assessments indicated that high dewatering rates resulted in FoS below one for potential failure surfaces through the coralline sediments. Considering the demonstrated stability of the slope in dewatered steady state conditions prior to flooding, this is concluded to be due to the slow rate at which water can drain from (and pore pressure can dissipate within) the coralline sediments due to its low hydraulic conductivity. Pore pressures therefore remained high thus relatively decreasing resistant forces along interpreted potential failure planes.

Several potential dewatering strategies were simulated using the iterative groundwater-stability modelling approach to determine the most appropriate dewatering rate. These included the approach of rapidly pumping down the pit lake by a specific increment to assess the potential impacts of elevated pore pressure gradients, followed by a period of reduced pumping to maintain the pit lake level to allow for pore pressure dissipation to 'catch up'. Through the modelling trials it became clear that slower continuous drawdown of the pit lake was the most effective method of maintaining adequate stability and confidence in the integrity of the slope during dewatering.

The following range of pit lake drawdown rates was initially considered in order to evaluate potential effects on slope stability:

- $500 \mathrm{~mm} /$ day.

- $300 \mathrm{~mm} /$ day.

- $200 \mathrm{~mm} /$ day.

- $100 \mathrm{~mm} /$ day.

Due to the low strength and hydraulic conductivity of the coralline sediments, even low rates of dewatering resulted in marginal modelled FoS (i.e. close to one) as the pit lake was drawn down through the coralline sediment profile. As such the dewatering rate of $100 \mathrm{~mm} /$ day was adopted as a guide during initial reduction of the pit lake through the coralline sediment unit, assuming pore pressure dissipation by natural drainage of groundwater to the pit face.

Notwithstanding the low target rate for pit lake drawdown, hold points in the dewatering were scheduled (at -7.5 mRL and -10 mRL) in order to allow for:

- Additional relaxation of pore pressure during the hold period.

- More detailed assessments of how pore pressure distributions were reducing.

- Refined assessment of the impacts on dewatering and pore pressure on stability. 
At hold points, the groundwater model was validated against monitoring data, pit lake level and VWP readings. The pore pressure data was used to update predicted pit wall stability. These were used to confirm expected future depressurisation/slope performance and to assess whether to extend the hold point or recommence dewatering.

As a result, an assessment process undertaken at the second hold point (at $-10 \mathrm{mRL}$ ) showed that dewatering could continue without any significant delay.

\subsubsection{Slope geometry}

The potential for increased dewatering rates to be achieved as a result of changes in slope geometry was investigated. Once the pit lake level had been drawn down to near the elevations of the $5 \mathrm{~m}$ wide berms, at $-10 \mathrm{mRL}$ and $-20 \mathrm{mRL}$, the berms began to have an increased beneficial influence on modelled stability. The initial increase in modelled FoS was marginal when the elevation of the pit lake was equal to berm elevation. However, as the pit lake reduced below the $-10 \mathrm{mRL}$ berm and once it had been drawn down to $-11 \mathrm{mRL}$ the calculated FoS for potential failure surfaces intersecting the slope profile increased significantly (by approximately $5 \%$ ). Based on this outcome, it was possible to increase the rate of dewatering to $150 \mathrm{~mm} /$ day from this point.

\subsubsection{Dewatering rate through different material types}

The potential to increase dewatering rates through higher strength materials underlying the coralline sediments was also assessed. The groundwater model was used to predict pore pressure dissipation for various increased dewatering rates, and the results used in the slope stability model to assess the impacts as the level of the pit lake was drawn down through these stronger material horizons.

Higher dewatering rates were modelled below $-13 \mathrm{mRL}$ where the top of the marine sediments unit intersects the pit face. Results indicated that stability within the coralline sediment unit continued to improve as a result of diminishing pore pressure and that the dewatering rate could be increased to $200 \mathrm{~mm} /$ day. Similarly, modelling results indicated that the dewatering rate could again be increased to $250 \mathrm{~mm} /$ day below $-16 \mathrm{mRL}$ as the pit lake intersected the hematite scree and elgee siltstone materials along the pit face. The final target dewatering schedule according to pit lake elevation (mRL) is shown in Table 5.

Table 5 Final dewatering rate schedule

\begin{tabular}{lll}
\hline \multicolumn{2}{l|}{ Pit lake elevation } & Dewatering \\
\hline From & To & rate \\
\hline$-4.2 \mathrm{mRL}$ & $-11 \mathrm{mRL}$ & $100 \mathrm{~mm} /$ day \\
$-11 \mathrm{mRL}$ & $-13 \mathrm{mRL}$ & $150 \mathrm{~mm} /$ day \\
$-13 \mathrm{mRL}$ & $-16 \mathrm{mRL}$ & $200 \mathrm{~mm} /$ day \\
$-16 \mathrm{mRL}$ & $-26 \mathrm{mRL}$ & $250 \mathrm{~mm} /$ day \\
$-26 \mathrm{mRL}$ & & $300 \mathrm{~mm} /$ day \\
\hline
\end{tabular}

\section{$6 \quad$ Monitoring during dewatering}

The ability to monitor progress was a critical factor in the success of the dewatering project. Monitoring consisted of collecting pore pressure readings at VWP sensor locations and tracking ground deformation over time during dewatering. This enabled observations of performance in the field to be incorporated into decision-making on how to progress with the planned approach to dewatering. It was also possible to create a trigger action response plan to assign actions required in case monitoring/movement thresholds were exceeded. The elevation of the pit lake was measured each morning using Trimble ${ }^{\mathrm{TM}}$ field survey equipment. 


\subsection{Pore pressure monitoring}

Pore pressure readings for VWP sensors in the field were collected via a datalogger telemetry system and interpreted on a regular basis. Readings were predominantly used to interpret how pore pressure was reducing in response to pit lake dewatering. Predictions of pore pressure reductions over time were also available from groundwater modelling for specific sensor locations. Since geotechnical stability models made use of modelled pore pressure distribution predictions it was important to understand performance in the field. Collected data was used to determine how closely field conditions were tracking compared to modelled (predicted) pore pressures used in geotechnical stability predictions. A close correlation of measured and predicted pore pressure values (i.e. good model calibration and/or validation) provided an indication that stability predictions were more likely to be reliable. Where deviations occurred, this provided an indication of whether stability predictions were likely to be either aggressive or conservative. Pore pressure observations therefore helped determine the potential to either increase or decrease the rate of dewatering in the pit.

Figure 5 provides an example of the achieved correlation between predicted and actual pore pressures at sensor PV376B as a result of final calibration of the groundwater model (i.e. run K2). The level of the pit lake during inundation and dewatering is also shown.

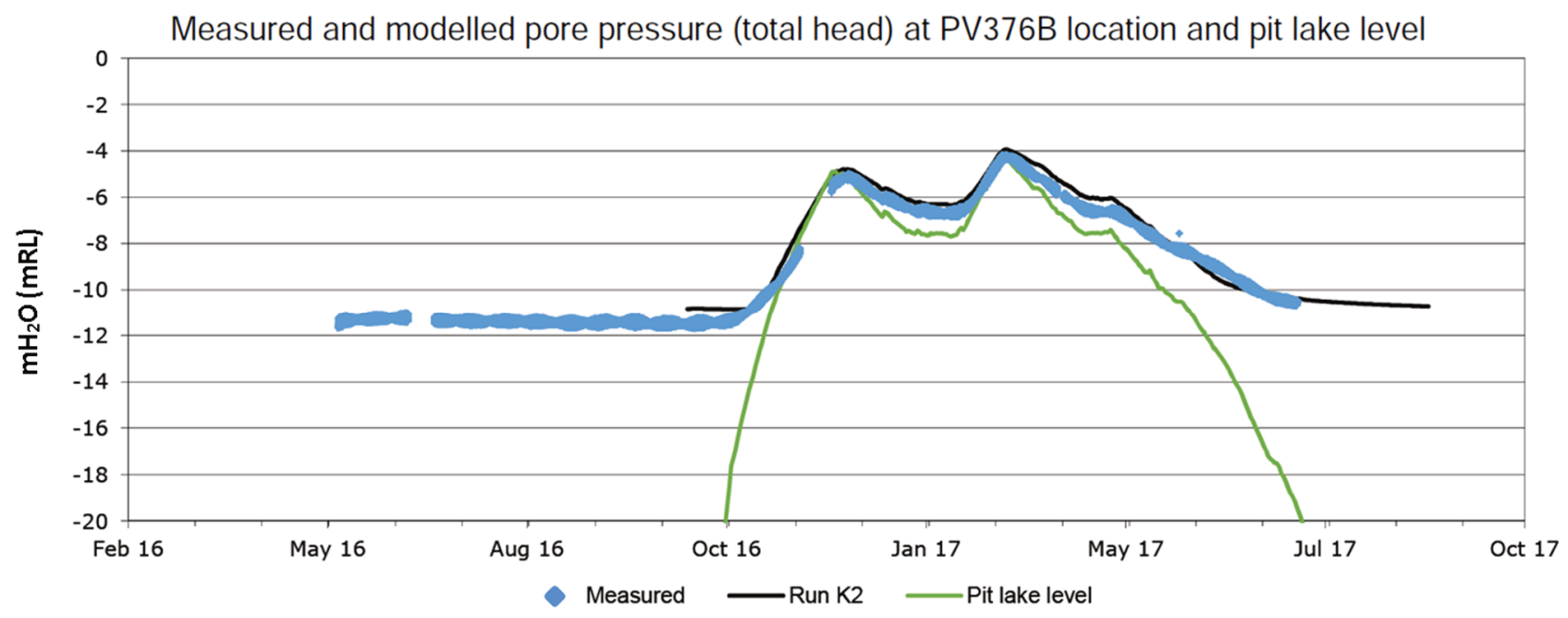

Figure 5 Example of final calibration output (K2) at sensor location PV376B compared with measured pore pressure and rising/falling lake levels during pit inundation and dewatering

\subsection{Deformation monitoring}

Deformation monitoring was used to keep track of ground movements indicative of potential larger scale instability. Several methods were used to keep track of ground deformation, these are:

- Slope stability radar (SSR) monitoring.

- Prism monitoring using automated Total Stations.

- Wire extensometers deployed over surface cracking.

- Daily visual inspections.

\subsubsection{Slope stability radar}

Two Reutech ${ }^{\text {TM }}$ SSRs were deployed onsite to offer adequate monitoring coverage across the seawall and hanging wall slope. These were positioned at strategic locations above the footwall slope. On-board generators enabled un-interrupted scanning of the slope. The live data feed was transferred back to a base station computer located in the site offices via a Wi-Fi radio connection. Reutech's proprietary Movement and Surveying Radar software provided an interface used to set deformation limits that would trigger 
alarms when surpassed. Audible alarms were set to transmit warning messages over the site handheld radio system when high alert alarms were triggered and these were tested at intervals to verify they were working.

Alarms were able to be set according to rate of change of movement and also according to the total change in distance between the radar and the area being monitored. Ground deformation was queried according to the average amount of movement over an area of designated size. Alarm thresholds were set by designating movement threshold limits and also the size of the area along the slope surface to be considered.

Exclusion zones were required to be assigned to certain areas of the slope being monitored. These included roads and areas where work activity was underway. It was noticed that fluctuations in-pit water level affected radar readings therefore a monitoring exclusion zone was also set-up for the pit lake to guard against false alarms. Consequently, exclusion zone delineations needed to be re-assessed as dewatering progressed. This ensured that newly exposed areas fell within radar monitoring boundaries.

\subsubsection{Prism monitoring}

Prism monitoring was undertaken using two automated Total Stations with rounds initiated each 45 minutes. Total Stations were set-up near each of the SSR locations and enabled readings at prism locations along pit-side seawall slope and the hanging wall slope beneath. Many of the prisms initially installed along the slope had gone underwater during inundation of the pit. Some of these were able to be rehabilitated however new prisms were also deployed as the water receded during dewatering in order to provide sufficient coverage. Prism monitoring data was regularly reviewed and provided good indications of ground deformation at the location of each prism. Readings of movement were also cross referenced with radar readings to provide greater confidence and correlation. Some daily fluctuation in deformation readings was noticed in both radar and prism readings due to thermal activity/atmospherics.

\subsubsection{Wire extensometers}

Wire extensometers were deployed across surface cracking to measure crack dilation. Readings were collected daily in areas of high importance. Tension cracks were mainly noticed to develop in areas related to where the pit had been infilled with waste. As these areas became saturated and then released water during pit lake drawdown, material redistribution resulted in settlement and cracking occurred at transitions to solid ground.

\subsubsection{Daily visual inspections}

Daily inspections were undertaken to supplement other types of monitoring, observe potential change in areas where no other methods of monitoring were possible and assess hot spot areas for changes that other monitoring techniques may not have been able to fully quantify. Visual observations also helped provide familiarity with any ongoing changes occurring. Timestamped photos were taken for reference from designated viewpoints during each inspection.

\section{$7 \quad$ Outcomes of dewatering}

Although some ground deformation was observed and measured at different times and places along the hanging wall side of the pit, the controlled dewatering approach helped to limit any potential significant instability. The pit was successfully dewatered through the sediment and saprolite units to competent rock in approximately five months. Over five gigalitres were pumped out during this time. In-pit logistics and other operational concerns caused some slowdown of pit dewatering after the pit lake was reduced below $-26 \mathrm{mRL}$, the elevation of the top of competent rock.

The dewatering procedure attempted to follow the target pit lake drawdown rates, however, actual achieved rates varied. This was in part due to changes in tidal inflows during transitions from spring to neap 
tides and due to practical aspects related to pumping infrastructure constraints. On average though, it was possible to maintain steady pit lake drawdowns.

A key outcome was that DMIRS was satisfied with the result of dewatering. Daily site inspection and progress reports were sent to DMIRS during dewatering due to the elevated risk profile and potential consequences of instability.

Confidence in site conditions resulting from the dewatering project also contributed to the planning phase of a pit cut-back on the hanging wall side of the pit. This was helped by the availability of measured pore pressure distribution data collected from VWP sensors during pit inundation and subsequent dewatering. The additional data enabled further calibration of the groundwater model and a greater understanding of conditions within the hanging wall slope.

\section{$8 \quad$ Pit cut-back}

Recommencement of mining operations within the pit required the hanging wall side of the pit to be cut back to extend mine life. This was considered within the Stage 3 area of the pit where sheet piles had been used as part of the low permeability barrier within the seawall. Although the width of the planned cut-back was relatively small, designed to minimise impact on the integrity of the seawall embankment and hanging wall of the pit, the cut-back would yield a significant amount of ore due to the length along strike. The pit optimisation study resulted in an additional $2 \mathrm{Mt}$ of ore, extending the mine life by up to two years.

The key factor in selection of the cut-back design was slope stability. Several different potential pit geometries were assessed prior to adopting a geometry that was suitable from a geotechnical perspective while maximising the amount of ore made available. During the course of the study a passive sand drain solution was developed to aid dissipation of pore pressures and increase slope stability during and after cut-back excavations.

\subsection{Sand drains}

The sand drain solution was developed to reduce pore pressure distribution through the slope profile by opening up drainage pathways through the coralline sediments to underlying materials with higher hydraulic conductivity. Large diameter vertical drains were designed to intersect the hematite scree layer between $20 \mathrm{~m}$ and $25 \mathrm{~m}$ below installation level. A modified version of the groundwater model was used to assess various drain spacings for vertical, sand filled boreholes to be installed along a constructed berm at $0 \mathrm{mRL}$. Different diameter sand drains were considered, and $350 \mathrm{~mm}$ diameters were selected. An allowance was made within design for a downhole pump to be installed if required (by casing the hole with $150 \mathrm{~mm}$ diameter slotted PVC with only the annulus being sand/gravel packed to enhance depressurisation) in case the targeted drainage layer (hematite scree) was not encountered at any particular location.

\subsection{Groundwater modelling}

An important part of the cut-back study was to adequately evaluate how pore pressure distributions would impact slope stability and to predict the relative performance of vertical drain separations.

In order to understand the potential impacts of individual sand drains, the existing 2D vertical slice model was used to simulate the pore pressure dissipation resulting from drainage from the coralline sediments to the underlying hematite scree (via a sand drain) and then by free drainage from the hematite scree to the pit face. Model output is reproduced in Figure 6 showing the predicted effect on pore pressures along the modelled section 30 days after installation of drains. 


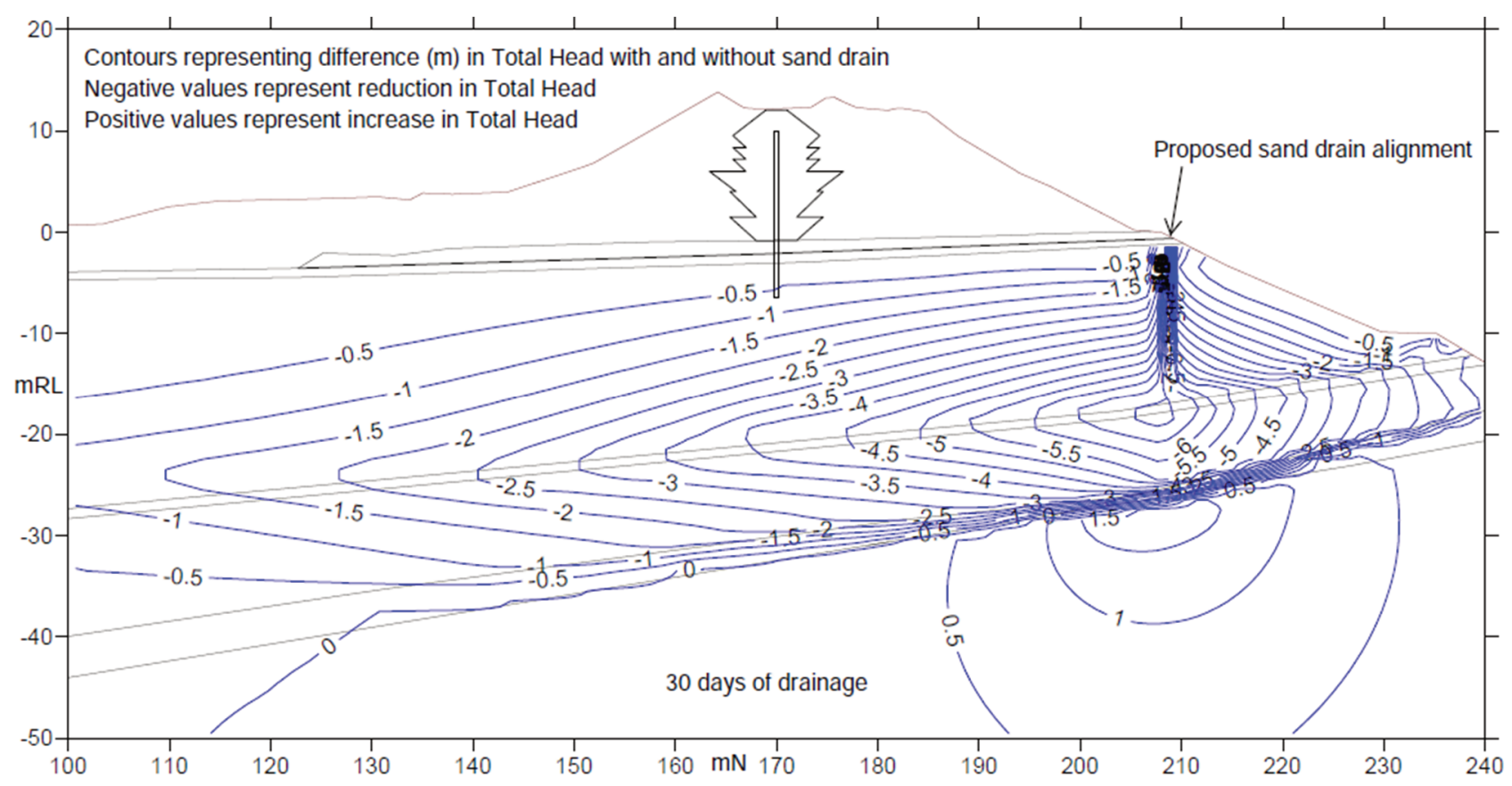

Figure $6 \quad 2 \mathrm{D}$ groundwater model output showing pore pressure reaction to sand drain

To assess the drawdown impacts of each drain along strike, and thus the required drain separation to achieve target drawdown at the mid-point between drains, a pseudo-3D modelling approach was adopted. This involved developing a 3D model based on the existing 2D vertical slice model and extending the 2D model geometry along strike (i.e. east-west) to form a 3D model grid and 3D hydrogeological unit distribution.

Two different drain spacings were considered, $10 \mathrm{~m}$ and $20 \mathrm{~m}$. An example comparing pore pressure reductions at the mid-point between two drains for $10 \mathrm{~m}$ and $20 \mathrm{~m}$ spaced drain arrays is shown in Figure 7. Pore pressure distributions (at mid-points) were predicted at various time step intervals and then imported into the slope stability model for evaluation of the impact of drain separation on pit wall stability.

Drain separations of $10 \mathrm{~m}$ were selected to achieve adequate pore pressure reductions.

\subsection{Assessment of mining schedule}

The groundwater model was also used to predict pore pressure distributions at key periods during the planned cut-back excavation. Based on the modelling results (both groundwater and slope stability), a mining schedule was developed that would maintain an adequate FoS $(>1.3)$ over the LOM. 


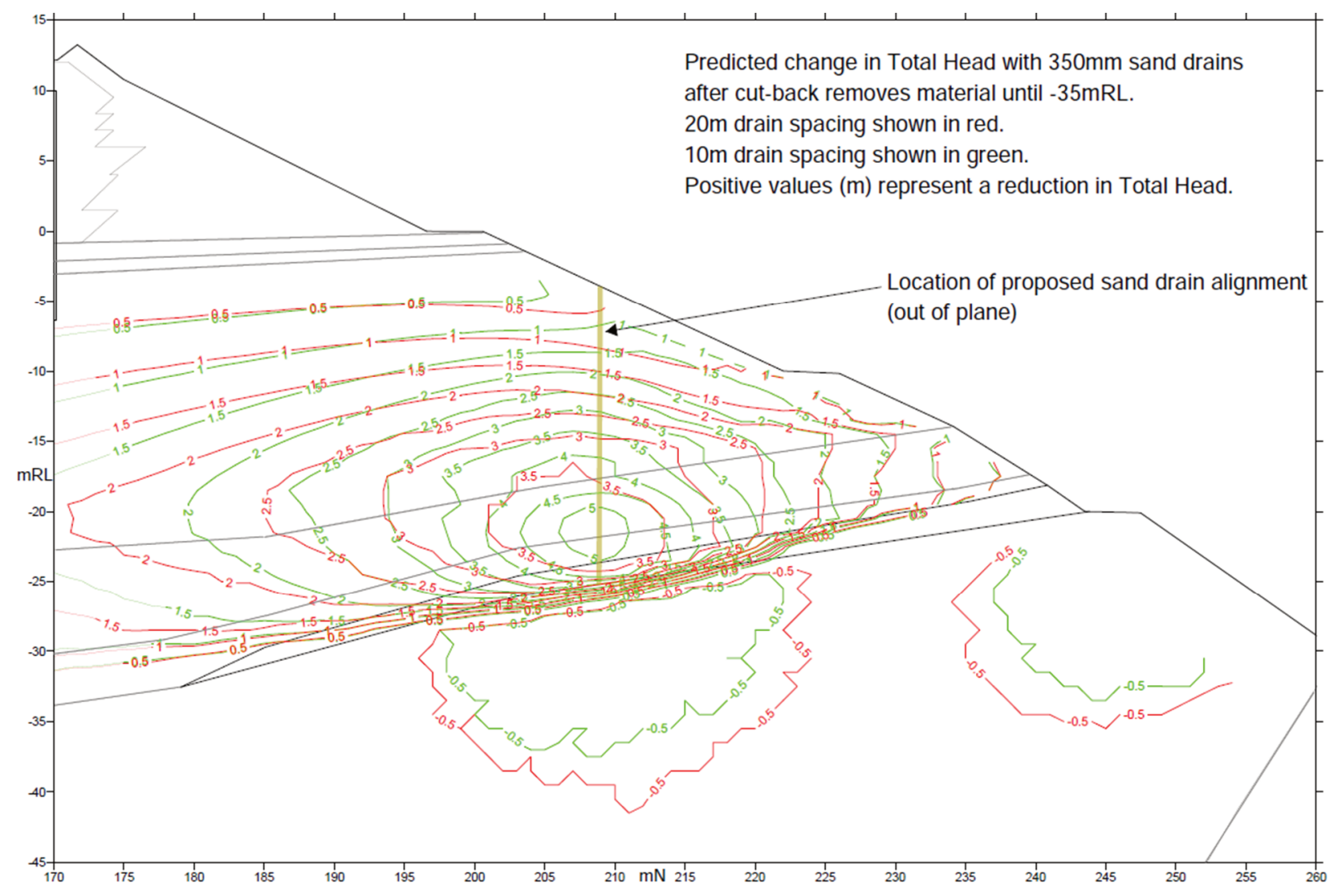

Figure 7 Cross-section of 3D groundwater model output showing pore pressure response at mid-point between sand drain locations along strike for $10 \mathrm{~m}$ and $20 \mathrm{~m}$ drain separations

\section{Conclusion}

The combined approach of developing and being able to integrate groundwater and slope stability modelling helped develop a dewatering and mining strategy that met both safety requirements (adequate FoS over the LOM) and provided adequate commercial return. The observational approach that was adopted also proved to be very effective in providing feedback from various monitoring facilities to quantity performance in the field. This provided the opportunity to modify day-to-day actions according to observations. It also allowed for the validation (and recalibration where required) of predictive models, the ongoing refined prediction of future slope performance and modifications to longer-term depressurisation and mining as required. Together these methods provided effective predictive and evaluation tools during planning and implementation phases of dewatering.

The integration of groundwater and slope stability models also helped in developing the sand drain strategy during the pit cut-back optimisation study.

These successes helped to provide an opportunity for the mine to recommence operations. Unfortunately, despite the positive outcomes of the dewatering and the pit optimisation study, other factors resulted in the mine remaining under care and maintenance and the pit has been allowed to flood once again. However, the lessons learned from the studies completed to date and the experience of recent pit lake dewatering, provides a practical (and proven in part) dewatering and mining strategy if/when mining operations recommence.

\section{References}

Smith, KR 1979, The Great Challenge: The Saga of Yampi, self-published, Perth.

Sullivan, TD 2007, 'Hydromechanical coupling and pit slope movements', in Y Potvin (ed.), Proceedings of the 2007 International Symposium on Rock Slope Stability in Open Pit Mining and Civil Engineering, Australian Centre for Geomechanics, Perth, pp. 3-43. 